\title{
Genetic susceptibility for chronic bronchitis in chronic obstructive pulmonary disease
}

\author{
Jin Hwa Lee ${ }^{1,2^{*}}$, Michael H Cho ${ }^{1,3}$, Craig P Hersh ${ }^{1,3}$, Merry-Lynn N McDonald ${ }^{1}$, James D Crapo ${ }^{4}$, Per S Bakke ${ }^{5,6}$, \\ Amund Gulsvik ${ }^{5,6}$, Alejandro P Comellas ${ }^{7}$, Christine H Wendt ${ }^{8}$, David A Lomas ${ }^{9}$, Victor Kim ${ }^{10}$, Edwin K Silverman ${ }^{1,3^{*}}$ \\ on behalf of the COPDGene and ECLIPSE Investigators
}

\begin{abstract}
Background: Chronic bronchitis (CB) is one of the classic phenotypes of COPD. The aims of our study were to investigate genetic variants associated with COPD subjects with CB relative to smokers with normal spirometry, and to assess for genetic differences between subjects with $C B$ and without CB within the COPD population.

Methods: We analyzed data from current and former smokers from three cohorts: the COPDGene Study; GenKOLS (Bergen, Norway); and the Evaluation of COPD Longitudinally to Identify Predictive Surrogate Endpoints (ECLIPSE). CB was defined as having a cough productive of phlegm on most days for at least 3 consecutive months per year for at least 2 consecutive years. CB COPD cases were defined as having both CB and at least moderate COPD based on spirometry. Our primary analysis used smokers with normal spirometry as controls; secondary analysis was performed using COPD subjects without CB as controls. Genotyping was performed on Illumina platforms; results were summarized using fixed-effect meta-analysis.
\end{abstract}

Results: For CB COPD relative to smoking controls, we identified a new genome-wide significant locus on chromosome 11 p15.5 (rs34391416, OR =1.93, P =4.99 $\times 10^{-8}$ ) as well as significant associations of known COPD SNPs within FAM13A. In addition, a GWAS of $C B$ relative to those without $C B$ within COPD subjects showed suggestive evidence for association on 1q23.3 ( $\mathrm{rs} 114931935, \mathrm{OR}=1.88, P=4.99 \times 10^{-7}$ ).

Conclusions: We found genome-wide significant associations with CB COPD on 4q22.1 (FAM13A) and 11p15.5 (EFCAB4A, CHID1 and AP2A2), and a locus associated with CB within COPD subjects on 1q23.3 (RPL31P11 and ATF6). This study provides further evidence that genetic variants may contribute to phenotypic heterogeneity of COPD.

Trial registration: ClinicalTrials.gov NCT00608764, NCT00292552

Keywords: Pulmonary disease, Chronic obstructive, Chronic bronchitis, Genome-wide association study

\section{Background}

COPD, a leading cause of morbidity and mortality, is characterized by persistent airflow limitation and phenotypic heterogeneity. While cigarette smoking is a major risk factor for COPD, the response to cigarette smoke is highly variable [1]. Chronic bronchitis (CB) and emphysema represent two classic phenotypes of COPD [2]. However, $\mathrm{CB}$, which is defined clinically by chronic cough and

\footnotetext{
* Correspondence: jinhwalee@ewha.ac.kr; ed.silverman@channing.harvard.edu ${ }^{1}$ Channing Division of Network Medicine, Brigham and Women's Hospital, Boston, MA, USA

${ }^{3}$ Division of Pulmonary and Critical Care Medicine, Brigham and Women's Hospital, Boston, MA, USA

Full list of author information is available at the end of the article
}

phlegm, can occur in the absence of COPD [3]. Some studies have suggested that $\mathrm{CB}$ and emphysema have different genetic determinants $[4,5]$. $\mathrm{CB}$ has been reported to be associated with frequent respiratory exacerbations, increased respiratory symptoms, poor quality of life, and even increased mortality [6-8].

Although candidate gene testing and linkage analysis have been used to search for CB-related genetic determinants in selected populations $[9,10]$ and recently a genome-wide association meta-analysis has reported genetic variants associated with chronic mucus hypersecretion mainly in subjects from the general population [11], genome-wide association studies (GWAS) of CB within COPD subjects have not been reported. Our 
primary hypothesis was that genetic variants would be associated with COPD-related CB. We also hypothesized that genetic heterogeneity exists according to the presence or absence of $\mathrm{CB}$ within COPD subjects. We addressed these hypotheses by comparing COPD subjects with $\mathrm{CB}$ to smokers with normal spirometry and to COPD subjects without $\mathrm{CB}$ as control groups.

\section{Methods}

\section{Study cohorts}

Subjects were current and former smokers from three studies: the non-Hispanic whites (NHWs) from the COPDGene Study (NCT00608764 at, https://clinicaltrials. gov); GenKOLS (Bergen, Norway); and the Evaluation of COPD Longitudinally to Identify Predictive Surrogate Endpoints (ECLIPSE, NCT00292552 at, https://clinicaltrials. gov). All subjects had self-described European white ancestry. The design and procedures for each participating study have been previously described [12-14]. For supplementary analysis, the African Americans (AAs) of the COPDGene Study were included. Institutional review board approval was obtained at each participating clinical center; all subjects provided written informed consent. This study was approved by the Partners HealthCare Institutional Review Board (COPDGene, 2007P000554; GenKOLS, 2009P000790; ECLIPSE, 2005P002467).

\section{Variable definitions}

$\mathrm{CB}$ was defined as chronic productive cough for 3 months in each of 2 successive years [15]. CB COPD cases were defined as having both $\mathrm{CB}$ and COPD of at least spirometry grade 2 (post-bronchodilator $\mathrm{FEV}_{1} / \mathrm{FVC}<0.7$ and $\mathrm{FEV}_{1}<80 \%$ predicted), defined by the Global initiative for chronic Obstructive Lung Disease (GOLD 2-4) [16]. For CB COPD cases, primary analysis used current or former smokers with normal spirometry (post-bronchodilator $\mathrm{FEV}_{1} / \mathrm{FVC} \geq 0.7$ and $\mathrm{FEV}_{1} \geq 80 \%$ predicted) as a control group. A secondary analysis was performed using COPD subjects without $\mathrm{CB}$ as controls to explore genetic heterogeneity within COPD subjects. Additionally, we performed GWAS of COPD subjects without $\mathrm{CB}$ relative to smoking controls for comparison to our results in COPD CB subjects (Figure 1). Additional variable definitions for complementary analyses are available in an online supplement.

\section{Genotyping quality control and imputation}

Genotyping was performed using Illumina platforms [HumanOmniExpress for the COPDGene cohort, the HumanHap 550 (V1, V3, and Duo) for the GenKOLS cohort, and HumanHap 550V3for the ECLIPSE cohort; Illumina, Inc., San Diego, CA]. Genotype imputation on the COPDGene cohorts was performed using $\mathrm{MaCH}$ [17] and minimac [18] using 1000 Genomes [19] Phase I v3 European (EUR) reference panels or cosmopolitan

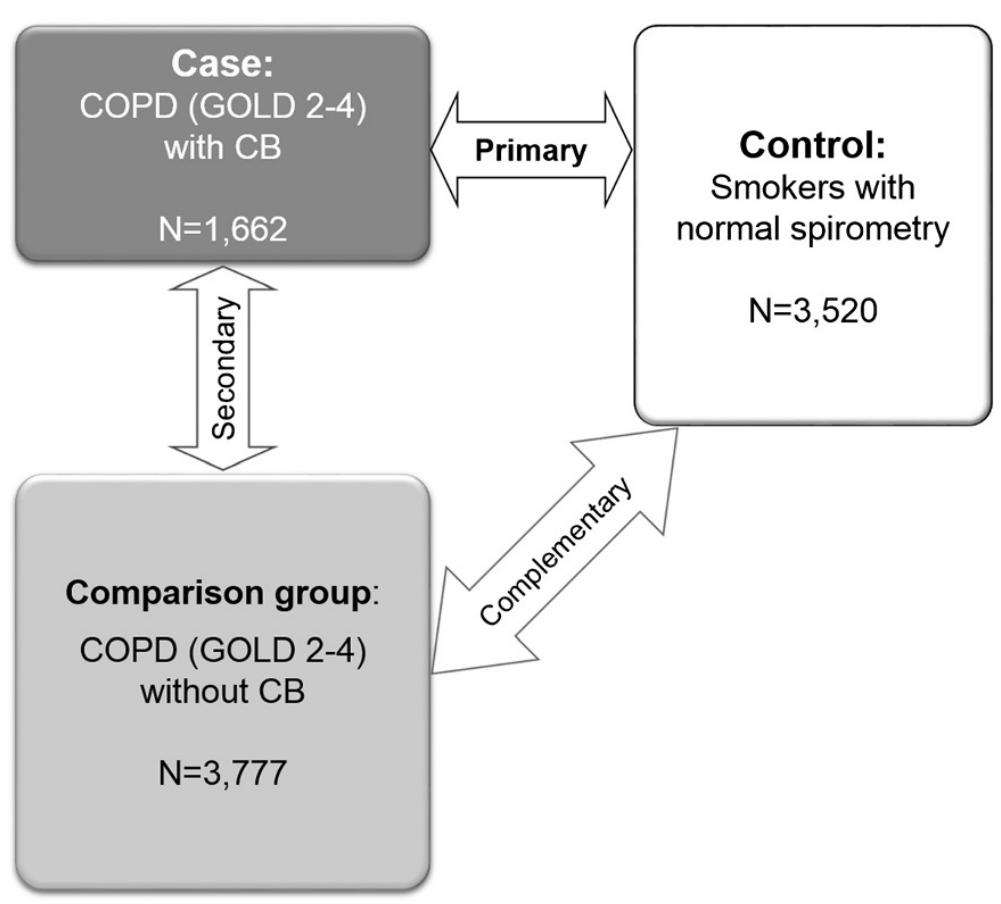

Figure 1 Genome-wide association study design for chronic bronchitis. Definition of abbreviations: $C B=$ chronic bronchitis; $C O P D=c h r o n i c$ obstructive pulmonary disease; GOLD = Global initiative for chronic Obstructive Lung Disease. GOLD 2-4 was defined as having a post-bronchodilator FEV1/FVC $<0.7$ and FEV1 $<80 \%$ predicted. Normal spirometry was defined as having a post-bronchodilator FEV1/FVC $\geq$ 0.7 and $\mathrm{FEV} 1 \geq 80 \%$ predicted. 
reference panels for NHWs and AAs, respectively. Details on genotyping quality control and imputation for the GenKOLS and ECLIPSE cohorts have been previously described $[5,14,20-23]$. If variants passed genotyping or imputation quality control in all three cohorts, they were included for analysis.

\section{Statistical analysis}

Logistic regression analysis of SNPs under an additive model of inheritance with case-control status as the outcome was performed in each cohort with adjustment for age, gender, pack-years of cigarette smoking and genetic ancestry-based principal components using PLINK 1.07 [24], as previously described [21-23]. Imputed genotypes were analyzed in a similar manner, using SNP dosage data in PLINK 1.07 [24]. We performed fixed-effects meta-analysis [25] using METAL (version 2011-3-25) [26] and R 2.15.1 (www.r-project.org) with the metapackage. Heterogeneity was assessed by calculating both $I^{2}$ [27] and $P$ values for Cochran's $Q$. In genomic regions with evidence of genetic heterogeneity, we also used a modified random-effects model optimized to detect associations under heterogeneity since the fixed effects model is based on inverse-variance-weighted effect size [28]. Genomic inflation factors [29] were calculated using GenABEL [30]. We used LocusZoom [31] to generate regional association plots, using the 1000 Genomes EUR reference data to calculate linkage disequilibrium (LD).

We used permutation testing [23] to assess differences in ORs of previous known genome-wide significant SNPs between two meta-analyses.

\section{Results}

\section{GWAS of CB COPD relative to smokers with normal spirometry}

Baseline characteristics of each of the three primary cohorts are summarized in Table 1.

For the primary analysis of $\mathrm{CB} C \mathrm{COPD}$ relative to smokers with normal spirometry, the combined GWAS of three cohorts included 1,662 CB COPD cases and
3,520 controls. The quantile-quantile (Q-Q) plot showed no evidence of significant residual population stratification (Figure $2 \mathrm{~A}$; lambda=1.03). Figure $3 \mathrm{~A}$ shows a genome-wide significant association within the previously reported COPD susceptibility genome-wide significant region on chromosome 4q22.1 in FAM13A and a second genome-wide significant association in a novel region on 11p15.5. The results for the most significant SNPs at each of these loci are listed in Table 2. Figure 4 displays the regional association plots for these two regions. The top $12 \mathrm{SNPs}$ in the meta-analysis were located on 4q22.1 (FAM13A) and either identical to, or in strong LD $\left(r^{2} \geq 0.97\right)$ with, the top SNPs previously described in GWASs of pulmonary function [32,33] and COPD [21-23].

The novel locus on 11p15.5 encompasses a region where three genes are annotated: EF-hand calcium binding domain $4 \mathrm{~A}(E F C A B 4 A)$, chitinase domain containing 1 (CHID1), and adaptor-related protein complex 2, alpha 2 subunit $(A P 2 A 2)$. The most significant SNP at this locus was rs34391416 (EFCAB4A), with a $P$ value of $4.99 \times 10^{-8}$. There was some evidence of heterogeneity $\left(P=0.01\right.$ for Cochran's $\left.Q, I^{2}=79\right)$. However, a metaanalysis using a modified random effects model showed more highly significant $P$ values: $P=1.66 \times 10^{-8}$ at rs34391416 (EFCAB4A), $P=7.56 \times 10^{-9}$ at $\mathrm{rs} 147862429$ (CHID1), and $P=1.11 \times 10^{-8}$ at rs143705409 (AP2A2).

\section{GWAS of CB COPD relative to COPD subjects without CB}

A GWAS of CB within COPD subjects from three studies included the same number of COPD CB cases and 3,777 COPD subjects without $\mathrm{CB}$ as a control group. Table 3 showed baseline characteristics of COPD subjects, and there is a corresponding Q-Q plot in Figure 2B (lambda $=1.01$ ). We found a novel suggestive locus on 1q23.3, which did not reach genome-wide significant levels (rs114931935, $P=4.99 \times 10^{-7}$, Table 4 and Figure 3B). This locus includes ribosomal protein L31 pseudogene 11 (RPL31P11) and activating transcription factor 6 (ATF6) (Figure 5).

Table 1 Baseline characteristics of COPD subjects with chronic bronchitis and smokers with normal spirometry as a control group

\begin{tabular}{|c|c|c|c|c|c|c|}
\hline & \multicolumn{2}{|c|}{ COPDGene NHWs } & \multicolumn{2}{|l|}{ GenKOLS } & \multicolumn{2}{|l|}{ ECLIPSE } \\
\hline & COPD with CB & Controls & COPD with CB & Controls & COPD with CB & Controls \\
\hline $\mathrm{n}$ & 844 & 2,534 & 311 & 808 & 507 & 178 \\
\hline Age, years & $62.8(8.3)$ & $59.5(8.7)$ & $65.3(10.0)$ & $55.6(9.7)$ & $62.3(7.7)$ & $57.5(9.4)$ \\
\hline Pack-years & $59.2(28.6)$ & $37.8(20.3)$ & $33.9(20.2)$ & 19.7 (13.6) & $51.6(30.2)$ & $32.1(24.8)$ \\
\hline Current smoker (\%) & 53.3 & 39.6 & 54.0 & 41.2 & 51.4 & 40.1 \\
\hline $\mathrm{FEV}_{1}, \%$ predicted & $48.6(17.4)$ & $96.8(11.0)$ & $46.9(16.8)$ & $94.9(9.2)$ & $46.3(15.3)$ & $107.9(13.7)$ \\
\hline Sex (\% male) & 61.8 & 49.3 & 64.6 & 50.1 & 75.7 & 57.9 \\
\hline
\end{tabular}

Data are presented as mean (SD) or percentage, as appropriate.

Definition of abbreviations: CB chronic bronchitis, NHW non-Hispanic white. 

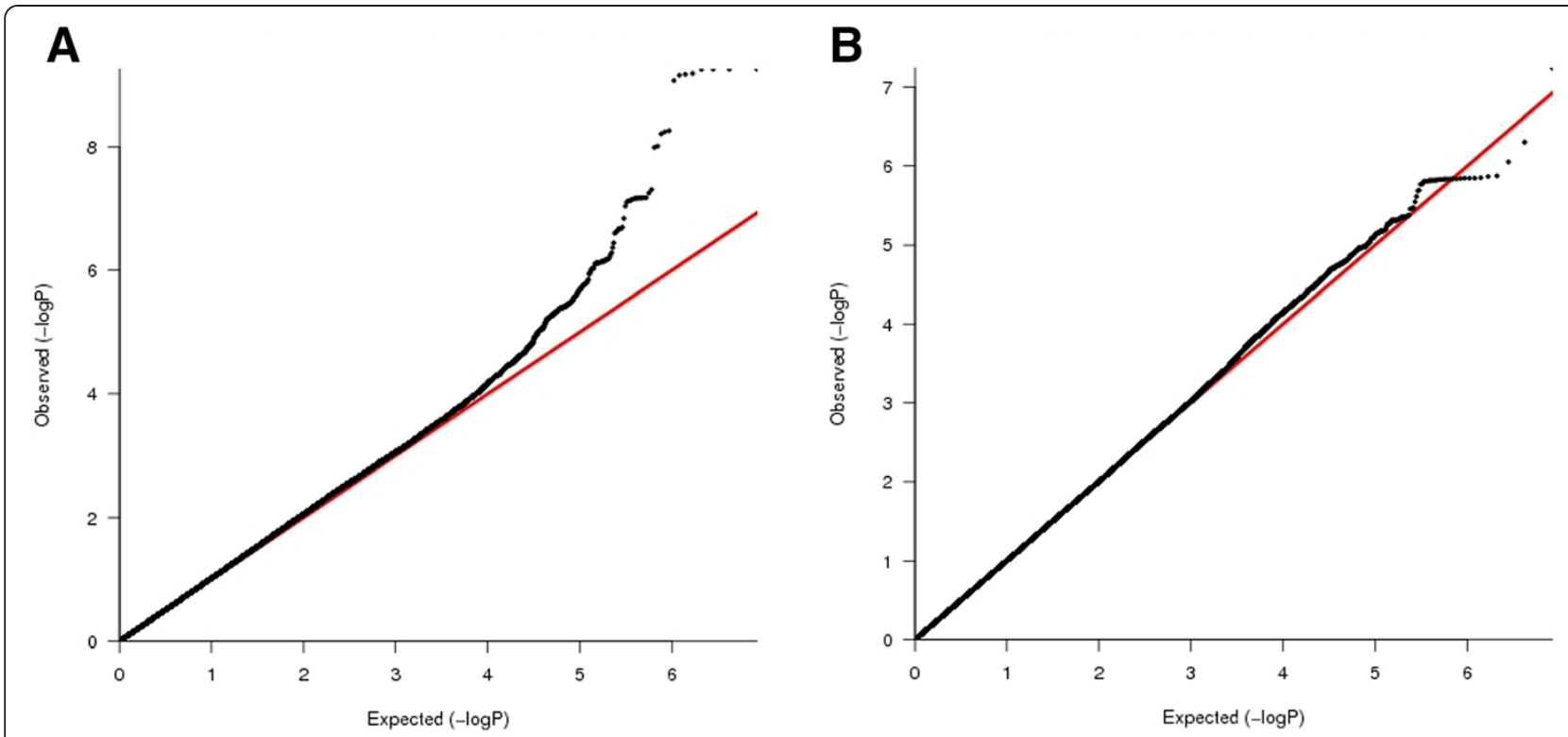

Figure 2 The quantile-quantile plots for the three-cohort meta-analysis including 1000 Genomes project imputed data for (A) COPD subjects with chronic bronchitis (CB) versus smoking controls and (B) CB versus no $C B$ within COPD subjects, after adjustment for age, sex, pack-years of cigarette smoking and genetic ancestry using principal components.

Since the GWAS in COPD Gene NHWs for COPD with $\mathrm{CB}$ versus $\mathrm{COPD}$ without $\mathrm{CB}$ identified a genome-wide significant SNP, rs12692398 on 2p25.1, we performed a meta-analysis of two studies (COPDGene NHWs and GenKOLS), which also demonstrated the same SNP as a genome-wide significant SNP (Additional file 1: Table S1 and Additional file 1: Figure S1). It is located within cystin-1 (CYS1), encoding a cilia-associated protein. This
SNP did not demonstrate evidence for association to $\mathrm{CB}$ within ECLIPSE COPD cases.

\section{Complementary analyses}

To explore whether our results were similar when including an additional racial group, a supplemental metaanalysis of four cohorts by adding AAs of COPDGene was performed for $\mathrm{CB}$ COPD relative to smoking
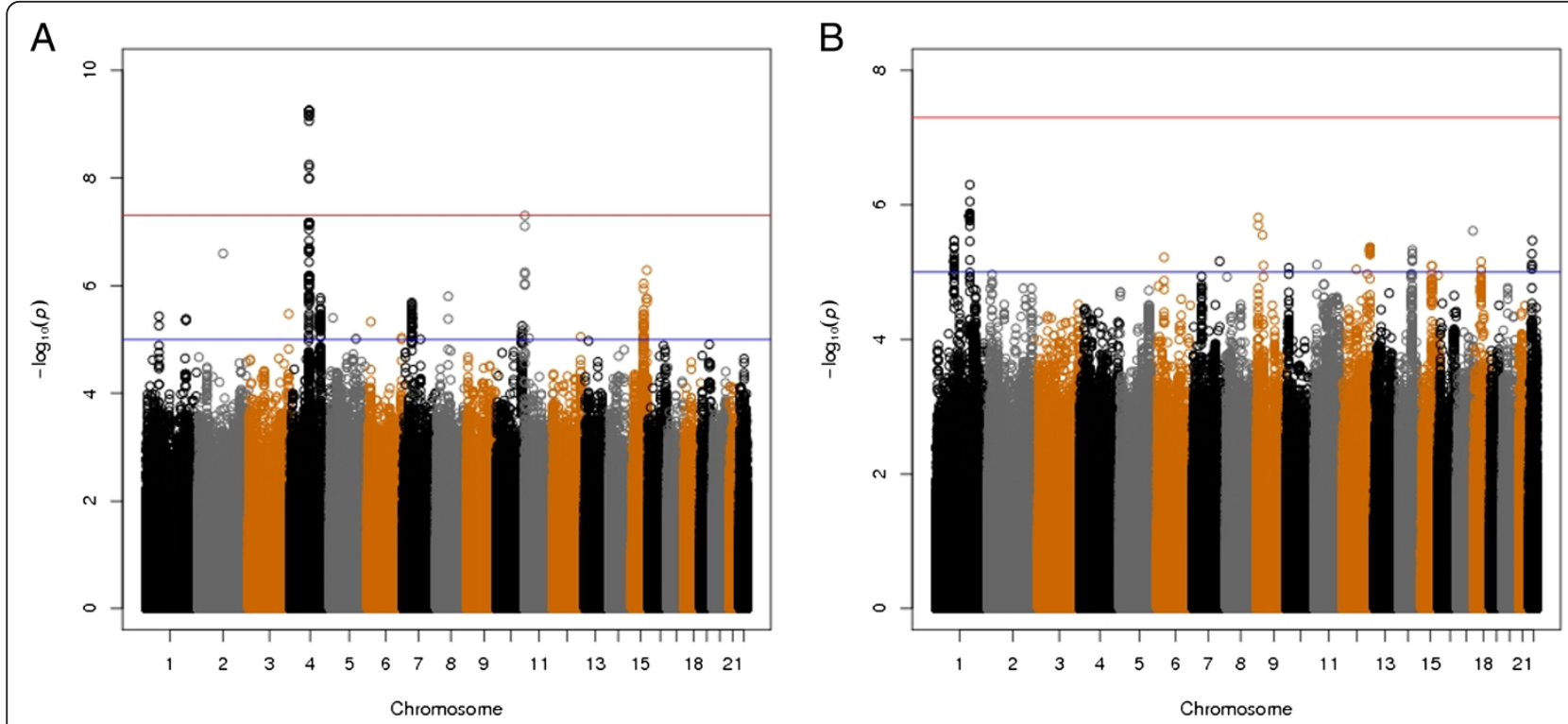

Figure 3 Manhattan plots of $-\log _{10} P$ values for meta-analysis of three cohorts for (A) COPD subjects with chronic bronchitis (CB) versus smoking controls and (B) CB versus no CB within COPD subjects, after adjustment for age, sex, pack-years of cigarette smoking and genetic ancestry using principal components. 
Table 2 Top results of the meta-analysis for COPD subjects with chronic bronchitis versus smokers with normal spirometry in COPDGene non-Hispanic white,

GenKOLS, and ECLIPSE studies*

\begin{tabular}{|c|c|c|c|c|c|c|c|c|c|c|c|c|c|c|}
\hline \multirow[t]{2}{*}{ Locus } & \multirow{2}{*}{$\begin{array}{l}\text { Nearest } \\
\text { gene }\end{array}$} & \multirow[t]{2}{*}{ SNP } & \multirow{2}{*}{$\begin{array}{l}\begin{array}{l}\text { Risk } \\
\text { allele }\end{array} \\
\end{array}$} & \multirow[t]{2}{*}{ FRQ } & \multicolumn{2}{|c|}{ COPDGene NHWs } & \multicolumn{2}{|l|}{ GenKOLS } & \multicolumn{2}{|l|}{ ECLIPSE } & \multicolumn{2}{|l|}{ Overall } & \multirow[b]{2}{*}{$r^{2}$} & \multirow[b]{2}{*}{$Q$} \\
\hline & & & & & OR $(95 \% \mathrm{Cl})$ & $P$ & OR $(95 \% \mathrm{Cl})$ & $P$ & OR (95 Cl) & $P$ & OR $(95 \% \mathrm{Cl})$ & $P$ & & \\
\hline $4 q 22$ & FAM13A & rs2869967 & C & 0.41 & $1.33(1.17-1.51)$ & $9.92 \times 10^{-6}$ & $1.56(1.25-1.95)$ & $8.08 \times 10^{-5}$ & $1.40(1.04-1.88)$ & $2.66 \times 10^{-2}$ & $1.38(1.25-1.53)$ & $5.61 \times 10^{-10}$ & 0 & 0.46 \\
\hline $4 q 22$ & FAM13A & rs2045517 & T & 0.40 & $1.33^{\dagger}(1.17-1.51)$ & $9.87 \times 10^{-6}$ & $.56^{\dagger}(1.25-1.95)$ & $7.88 \times 10^{-5}$ & $1.40^{\dagger}(1.04-1.88)$ & $57 \times 10^{-2}$ & $1.38(1.25-1.53)$ & $5.63 \times 10^{-10}$ & 0 & 0.46 \\
\hline $4 q 22$ & FAM13A & rs7671167 & $\mathrm{T}$ & 0.51 & $1.32(1.16-1.49)$ & $1.69 \times 10^{-5}$ & $1.44(1.15-1.80)$ & $1.27 \times 10^{-3}$ & $1.41(1.06-1.87)$ & $1.73 \times 10^{-2}$ & $1.35(1.22-1.50)$ & $5.58 \times 10^{-9}$ & 0 & 0.75 \\
\hline $4 q 22$ & FAM13A & rs2904259 & C & 0.50 & $1.31^{\dagger}(1.16-1.49)$ & $1.85 \times 10^{-5}$ & $1.44^{\dagger}(1.15-1.80)$ & $1.33 \times 10^{-3}$ & $1.41^{\dagger}(1.06-1.87)$ & $1.73 \times 10^{-2}$ & $1.35(1.22-1.49)$ & $6.25 \times 10^{-9}$ & 0 & 0.75 \\
\hline $11 \mathrm{p} 15$ & $E F C A B 4 A$ & rs34391416 & A & 0.05 & $2.38(1.81-3.13)$ & $6.11 \times 10^{-10}$ & $1.21^{\dagger}(0.68-2.16)$ & $5.18 \times 10^{-1}$ & $0.80^{\dagger}(0.35-1.79)$ & $5.79 \times 10^{-1}$ & $1.93(1.53-2.45)$ & $4.99 \times 10^{-8}$ & 79 & 0.01 \\
\hline $11 \mathrm{p} 15$ & CHID1 & rs 147862429 & T & 0.05 & $2.77^{\dagger}(2.02-3.81)$ & $2.90 \times 10^{-10}$ & $1.34^{\dagger}(0.71-2.53)$ & $3.68 \times 10^{-1}$ & $0.58^{\dagger}(0.24-1.39)$ & $2.23 \times 10^{-1}$ & $2.09(1.60-2.74)$ & $7.87 \times 10^{-8}$ & 85 & 0.001 \\
\hline $2 q 14$ & PCDP1 & rs139257032 & T & 0.02 & $2.78^{\dagger}(1.57-4.92)$ & $4.60 \times 10^{-4}$ & $4.17^{\dagger}(1.82-9.57)$ & $7.41 \times 10^{-4}$ & $10.79^{\dagger}(1.27-91.39$ & $2.91 \times 10^{-2}$ & $3.35(2.12-5.30)$ & $2.53 \times 10^{-7}$ & 0 & 0.4 \\
\hline $15 q 26$ & MCTP2 & rs12910412 & G & 0.46 & $1.29^{\dagger}(1.14-1.46)$ & $4.37 \times 10^{-5}$ & $1.30^{\dagger}(1.03-1.64)$ & $2.49 \times 10^{-2}$ & $1.33^{\dagger}(0.98-1.78)$ & $6.37 \times 10^{-2}$ & $1.30(1.17-1.44)$ & $5.22 \times 10^{-7}$ & 0 & 0.99 \\
\hline $11 \mathrm{p} 15$ & CHIDI & rs139090846 & T & 0.01 & $4.65^{\dagger}(2.77-7.80)$ & $5.67 \times 10^{-9}$ & $1.13^{\dagger}(0.33-3.89)$ & $8.41 \times 10^{-1}$ & $0.75^{\dagger}(0.19-2.91)$ & $6.78 \times 10^{-1}$ & $3.15(2.01-4.94)$ & $5.62 \times 10^{-7}$ & 78 & 0.01 \\
\hline $11 \mathrm{p} 15$ & $A P 2 A 2$ & rs143705409 & G & 0.05 & $2.62^{\dagger}(1.93-3.56)$ & $7.19 \times 10^{-10}$ & $1.32^{\dagger}(0.73-2.40)$ & $3.61 \times 10^{-1}$ & $0.52^{\dagger}(0.24-1.11)$ & $8.95 \times 10^{-2}$ & $1.92(1.49-2.49)$ & $6.16 \times 10^{-7}$ & 88 & 0.0002 \\
\hline 11p15 & $A P 2 A 2$ & rs 185 & C & 0.05 & $2.61^{\dagger}(1.92-3.54)$ & $8.44 \times 10^{-10}$ & $1.31^{\dagger}(0.73-2.35)$ & $4.26 \times 10^{-1}$ & $0.54^{\dagger}(0.26-1.11)$ & $9.50 \times 10^{-2}$ & $1.89(1.47-2.44)$ & $9.20 \times 10^{-7}$ & 88 & 0.0002 \\
\hline $11 \mathrm{p} 15$ & $A P 2 A 2$ & rs117455145 & G & 0.05 & $2.61^{\dagger}(1.92-3.54)$ & $8.50 \times 10^{-10}$ & $1.31^{\dagger}(0.73-2.34)$ & $4.27 \times 10^{-1}$ & $0.54^{\dagger}(0.26-1.11)$ & $9.28 \times 10^{-2}$ & $1.89(1.46-2.43)$ & $9.68 \times 10^{-7}$ & 88 & 0.0002 \\
\hline
\end{tabular}

Definition of abbreviations: $\mathrm{Cl}$ confidence interval, $F R Q$ risk allele frequency, $N H W$ non-Hispanic white, $O R$ odds ratio, SNP single nucleotide polymorphism.

"Adjusted for age, sex, pack-years of cigarette smoking and genetic ancestry as summarized in the principal components.

${ }^{+}$Imputed genotypes. 


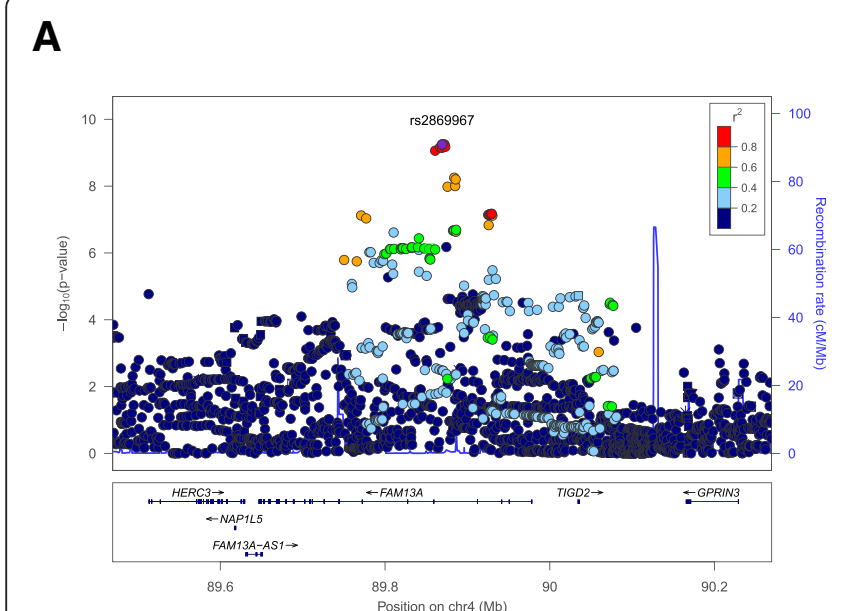

B

Figure 4 Local association plots for significant loci in the meta-analysis of cases with chronic bronchitis and COPD versus smoking control subjects in COPDGene non-Hispanic whites, GenKOLS, and ECLIPSE. A. rs2869967 on chromosome 4q22.1. B. rs34391416 on 11 p15.

The $x$-axis is chromosomal position, and the $y$-axis shows the -log10 P value. The most significant SNP at each locus is labeled in purple, with other SNPs colored by degree of linkage disequilibrium ( $r 2)$. Plots were created using LocusZoom.

controls. Additional file 1: Table S2 shows the baseline characteristics of AAs of COPDGene. The meta-analysis including 1,844 cases and 5,269 controls revealed similar results to those of three cohorts, with the exception of SNPs in both CHID and AP2A2, which were excluded because of their rarity in AA subjects (minor allele frequency $<0.01)$. The novel top SNP, rs34391416 $(E F C A B 4 A)$, was genome-wide significant $(\mathrm{OR}=1.93$, $\left.P=2.66 \times 10^{-8}\right)$.

Since CB was present in some of our smoking controls, a GWAS of CB COPD versus smoking controls without CB $(n=3,101)$ was performed for each of our three cohorts and then meta-analyzed. These results were similar, although the novel top SNP on 11p15.5 was slightly reduced in statistical significance (rs34391416, $\left.\mathrm{OR}=1.98, P=6.50 \times 10^{-8}\right)$. However, a meta-analysis of four cohorts including AAs of COPDGene $(n=4,628)$ showed genome-wide significance of the same SNP $(\mathrm{OR}=$ $\left.1.98, P=2.76 \times 10^{-8}\right)$. Baseline characteristics of smoking controls without $\mathrm{CB}$ were summarized in Additional file 1: Table S3.
Because COPD subjects with CB were more likely to be current smokers, complementary meta-analyses were performed with adjustment for current smoking status as well as age, gender, pack-years of cigarette smoking and genetic ancestry-based principal components. In metaanalyses using smokers with normal spirometry as a control group, FAM13A SNPs remained genome-wide significant. One of the previously reported COPD risk loci, $15 \mathrm{q} 25$, was nearly genome-wide significant $\left(P=6.58 \times 10^{-8}\right)$. However, the novel SNP on 11p15 (rs34391416) was not genomewide significant $\left(P=5.25 \times 10^{-7}\right.$ in three Caucasian cohorts and $P=2.60 \times 10^{-7}$ in four cohorts including AAs, Additional file 1: Table S4). On the other hand, a meta-analysis using COPD subjects without $\mathrm{CB}$ as a control group, with adjustment for current smoking status, provided lower (but not genome-wide significant) $P$ values of top SNPs from the secondary analysis of $\mathrm{COPD}$ with $\mathrm{CB}$ vs. $\mathrm{COPD}$ without $\mathrm{CB}$ (Additional file 1: Table S5).

We assessed the top SNPs of CB COPD susceptibility relative to smokers with normal spirometry (the primary

Table 3 Baseline characteristics of COPD subjects with chronic bronchitis (CB) and those without CB within each cohort

\begin{tabular}{|c|c|c|c|c|c|c|}
\hline & \multicolumn{2}{|c|}{ COPDGene NHWs } & \multicolumn{2}{|l|}{ GenKOLS } & \multicolumn{2}{|l|}{ ECLIPSE } \\
\hline & $\overline{\mathrm{CB}}$ & No CB & $\overline{\mathrm{CB}}$ & No CB & $\overline{\mathrm{CB}}$ & No $C B$ \\
\hline $\bar{N}$ & 844 & 1968 & 311 & 552 & 507 & 1257 \\
\hline Age, years & $62.8(8.3)$ & $65.5(8.0)$ & $65.3(10.0)$ & $65.7(10.1)$ & $62.3(7.7)$ & $64.2(6.8)$ \\
\hline Pack-years & $59.2(28.6)$ & $55.1(27.6)$ & $34.0(20.4)$ & $30.9(17.3)$ & $51.6(30.2)$ & $49.8(26.2)$ \\
\hline Current smoker (\%) & 53.3 & 26.7 & 54.0 & 42.8 & 51.4 & 28.5 \\
\hline $\mathrm{FEV}_{1}, \%$ predicted & $48.6(17.4)$ & $50.1(18.2)$ & $46.9(16.8)$ & $52.7(17.5)$ & $46.3(15.3)$ & $48.2(15.7)$ \\
\hline Sex (\% male) & 61.8 & 53.0 & 64.6 & 57.6 & 75.7 & 63.5 \\
\hline
\end{tabular}

Data are presented as mean (SD) or percentage, as appropriate.

Definition of abbreviations: CB chronic bronchitis, NHW Non-Hispanic white. 
Table 4 Top results of the meta-analysis for chronic bronchitis (CB) versus no CB within COPD subjects of COPDGene non-Hispanic white, GenKOLS, and ECLIPSE studies*

\begin{tabular}{|c|c|c|c|c|c|c|c|c|c|c|c|c|c|c|}
\hline \multirow[t]{2}{*}{ Locus } & \multirow{2}{*}{$\begin{array}{l}\text { Nearest } \\
\text { gene }\end{array}$} & \multirow[t]{2}{*}{ SNP } & \multirow{2}{*}{$\begin{array}{l}\text { Risk } \\
\text { allele }\end{array}$} & \multirow[t]{2}{*}{ FRQ } & \multicolumn{2}{|c|}{ COPDGene NHWs } & \multicolumn{2}{|l|}{ GenKOLS } & \multicolumn{2}{|l|}{ ECLIPSE } & \multicolumn{4}{|l|}{ Overall } \\
\hline & & & & & $\begin{array}{l}\text { OR } \\
(95 \% \mathrm{Cl})\end{array}$ & $P$ & $\begin{array}{l}\text { OR } \\
(95 \% \mathrm{Cl})\end{array}$ & $P$ & $\begin{array}{l}\text { OR } \\
(95 \% \mathrm{Cl})\end{array}$ & $P$ & $\begin{array}{l}\text { OR } \\
(95 \% \mathrm{Cl})\end{array}$ & $P$ & $I^{2}$ & $Q$ \\
\hline $1 q 23$ & RPL31P11 & rs114931935 & $A$ & 0.04 & $\begin{array}{l}1.98^{\dagger} \\
(1.42-2.78)\end{array}$ & $6.43 \times 10^{-5}$ & $\begin{array}{l}2.11^{\dagger} \\
(1.07-4.15)\end{array}$ & $3.10 \times 10^{-2}$ & $\begin{array}{l}1.64^{\dagger} \\
(1.07-2.51)\end{array}$ & $2.21 \times 10^{-2}$ & $\begin{array}{l}1.88 \\
(1.47-2.40)\end{array}$ & $4.99 \times 10^{-7}$ & 0 & 0.74 \\
\hline $1 q 23$ & RPL31P11 & rs114384494 & $\mathrm{T}$ & 0.04 & $\begin{array}{l}2.01^{\dagger} \\
(1.43-2.84)\end{array}$ & $7.04 \times 10^{-5}$ & $\begin{array}{l}2.18^{\dagger} \\
(1.08-4.38)\end{array}$ & $2.92 \times 10^{-2}$ & $\begin{array}{l}1.61^{\dagger} \\
(1.03-2.51)\end{array}$ & $3.62 \times 10^{-2}$ & $\begin{array}{l}1.89 \\
(1.47-2.44)\end{array}$ & $8.86 \times 10^{-7}$ & 0 & 0.67 \\
\hline $1 q 23$ & ATF6 & rs924777 & G & 0.12 & $\begin{array}{l}1.23^{\dagger} \\
(1.03-1.46)\end{array}$ & $2.20 \times 10^{-2}$ & $\begin{array}{l}1.21 \\
(0.89-1.64)\end{array}$ & $2.19 \times 10^{-1}$ & $\begin{array}{l}1.69 \\
(1.36-2.10)\end{array}$ & $2.30 \times 10^{-6}$ & $\begin{array}{l}1.36 \\
(1.20-1.54)\end{array}$ & $1.33 \times 10^{-6}$ & 65 & 0.06 \\
\hline $1 q 23$ & ATF6 & rs2298019 & A & 0.12 & $\begin{array}{l}1.23^{\dagger} \\
(1.03-1.47)\end{array}$ & $1.98 \times 10^{-2}$ & $\begin{array}{l}1.25^{\dagger} \\
(0.93-1.70)\end{array}$ & $1.43 \times 10^{-1}$ & $\begin{array}{l}1.66^{\dagger} \\
(1.33-2.06)\end{array}$ & $6.41 \times 10^{-6}$ & $\begin{array}{l}1.36 \\
(1.20-1.54)\end{array}$ & $1.36 \times 10^{-6}$ & 56 & 0.10 \\
\hline
\end{tabular}

Definition of abbreviations: $C l$ confidence interval, $F R Q$ risk allele frequency, NHW non-Hispanic white, $O R$ odds ratio, SNP single nucleotide polymorphism. *Adjusted for age, sex, pack-years of cigarette smoking and genetic ancestry as summarized in the principal components.

${ }^{\dagger}$ Imputed genotypes.

meta-analysis) in the results of the secondary metaanalysis of $\mathrm{CB}$ vs. no $\mathrm{CB}$ within $\mathrm{COPD}$ subjects. The novel SNPs on $11 \mathrm{p} 15.5$ were nominally significant $(P<$ $0.01)$, whereas SNPs near FAM13A were not significant $(P>0.1)$ (Additional file 1: Table S6).

Clinical and radiological characteristics were compared according to genotypes of rs34391416 among all COPDGene NHW subjects (Additional file 1: Table S7). There were significant differences in parameters related to airway disease, including airway wall area\% on inspiratory chest CT scans and gas trapping on expiratory CT. There were no differences in emphysema severity or distribution related to this SNP.

Since the meta-analysis of CB COPD relative to smoking controls showed FAM13A as the top gene, we performed additional analyses to ascertain whether SNPs near FAM13A had different levels of statistical significance between $C O P D$ with $\mathrm{CB}$ and $\mathrm{COPD}$ without $\mathrm{CB}$. A meta- analysis of GWASs for COPD subjects without CB relative to smoking controls (Figure 1) also showed FAM13A as the top gene, which was followed by HHIP and IREB2 (Additional file 1: Table S8 and Additional file 1: Figure S2). ORs and $P$ values of previously known COPD risk alleles among our results from meta-analyses for CB COPD or COPD without CB are summarized in Table 5. Permutation testing revealed that differences of ORs between our two meta-analyses were statistically significant at four SNPs in FAM13A.

\section{Discussion}

Our GWAS meta-analysis of three studies of COPD subjects with $\mathrm{CB}$ relative to smoking controls not only reconfirmed previously known genome-wide significant SNPs in FAM13A related to lung function [32,33] and COPD [21-23], but also revealed a novel locus on 11p15.5, including EFCAB4A, CHID1, and AP2A2.
A

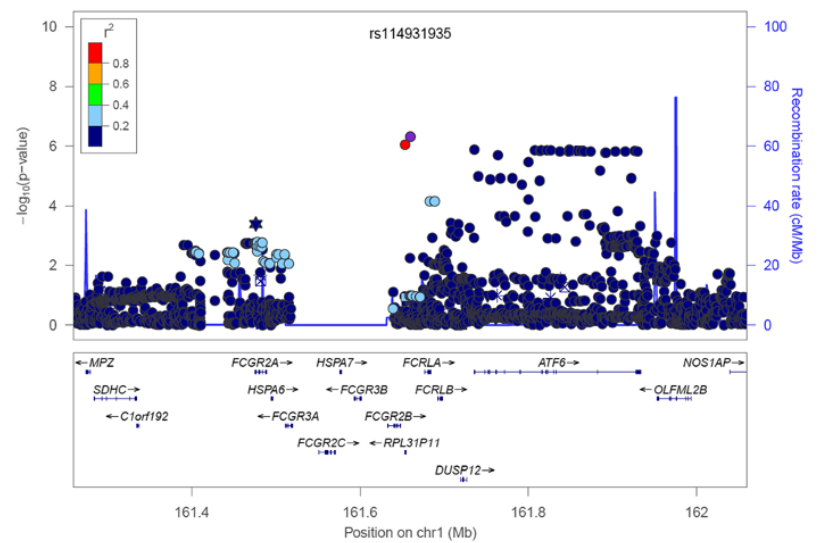

B

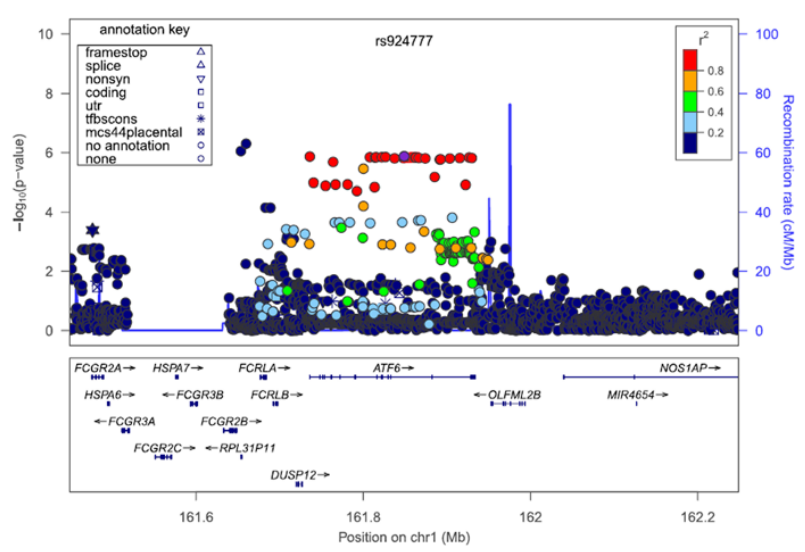

Figure 5 Local association plots for the top two loci in the meta-analysis of COPD subjects with chronic bronchitis versus COPD subjects without chronic bronchitis in COPDGene non-Hispanic whites, GenKOLS, and ECLIPSE. A. rS114931935 on 1923. B. rs924777 on 1q23. The $\mathrm{x}$-axis is chromosomal position, and the $\mathrm{y}$-axis shows the -log10 P value. The most significant SNP at each gene is labeled in purple, with other SNPs colored by degree of linkage disequilibrium (r2). Plots were created using LocusZoom. 
Proteins encoded by one or more of these three genes could be involved in $\mathrm{CB}$. Interestingly, this new region is located next to MUC6 and MUC2 (Figure 5) [34]. Thus, it is also possible that this genomic region influences regulation of mucin genes to alter susceptibility to $\mathrm{CB}$.

$E F C A B 4 A$ encodes a protein involved in store-operated $\mathrm{Ca}^{2+}$ entry. Intracellular $\mathrm{Ca}^{2+}$ was reported to regulate $M U C 2$ expression [34,35] and mucin secretion from airway goblet cells [36]. In addition, a study demonstrated increased intracellular $\mathrm{Ca}^{2+}$ levels in lymphocytes of COPD patients, which correlated positively with the spirometric grade of COPD [37]. Gene expression microarray analysis of human bronchial epithelial cells identified overexpression of EFCAB4A during mucociliary differentiation [38]. While quantitative RT-PCR revealed high expression of EFCAB4A in lung [39], a role for EFCAB4A in CB remains to be defined.

Even though SNPs near CHID1 in the meta-analysis of three GWASs did not show genome-wide significance, rs147862429 was the most genome-wide significant in a GWAS of COPDGene NHWs, with a $P$ value of $2.90 \times$ $10^{-10}$. CHID1 encodes a saccharide- and LPS-binding protein, also called stabilin-1 interacting chitinase-like protein (S1-CLP), with possible roles in pathogen sensing and endotoxin neutralization [40]. It is expressed in cells of monocytic, T lymphocyte, B lymphocyte, and epithelial origin, and it is up-regulated by the Th2 cytokine interleukin-4 and dexamethasone in macrophages [41].
Other human chitinase and chitinase-like proteins were previously suggested to play a role in the development of COPD [42]. Chitotriosidase (CHIT1) levels were elevated in the bronchoalveolar lavage fluid of smokers with COPD [43]. A chitinase-like protein, commonly known as YKL40, was also increased in the lungs of COPD patients [44]. A recent study demonstrated genetic associations between chitinase gene variants and lung function level and rate of decline in COPD patients from the Lung Health Study [45]. Therefore, CHID1 may be involved in the pathogenesis of $\mathrm{CB}$.

$A P 2 A 2$ encodes adaptor protein complex 2 subunit alpha-2, which has been shown to participate in the endocytosis of clathrin-coated vesicles in interacting with epsin-1 [46] and receptor endocytosis with SHCtransforming protein 1 [47]. One study demonstrated long-range interactions between the $M U C 2$ promoter and the adjacent $A P 2 A 2$ gene by using quantitative chromosome conformation capture (q3C) [48]. Although human respiratory tract mucus contains mainly MUC5AC and MUC5B along with smaller amounts of MUC2, the distribution of $M U C 2$ variable number tandem repeat (VNTR) alleles was reported to be different between asthmatics and non-asthmatics [49]. A followup study demonstrated relatively strong LD between SNPs in $M U C 2$ and $M U C 5 A C$ [50]. Therefore, AP2A2, either alone or through interactions with $M U C 2$, may have a potential role in $\mathrm{CB}$ pathogenesis.

Table 5 Meta-analysis results of COPD with chronic bronchitis (CB) vs. smoking controls and COPD without CB vs. smoking controls for COPD risk alleles previously demonstrated in genome-wide association studies of COPD vs. smoking controls

\begin{tabular}{|c|c|c|c|c|c|c|c|c|c|c|}
\hline \multirow[t]{2}{*}{ Locus } & \multirow[t]{2}{*}{ Gene } & \multirow[t]{2}{*}{ SNP } & \multirow[t]{2}{*}{$\begin{array}{l}\text { Risk } \\
\text { allele }\end{array}$} & \multicolumn{3}{|c|}{$\begin{array}{l}\text { COPD with CB vs. } \\
\text { smoking controls }\end{array}$} & \multicolumn{3}{|c|}{$\begin{array}{l}\text { COPD without CB vs. } \\
\text { smoking controls }\end{array}$} & \multirow{2}{*}{$\begin{array}{l}\text { Permutation testing to assess difference of OR } \\
\text { between two meta-analyses, } 10,000 \text { times } \\
P\end{array}$} \\
\hline & & & & FRQ & OR & $P$ & FRQ & OR & $P$ & \\
\hline $4 q 22$ & FAM13A & rs2869967* & $C$ & 0.41 & 1.38 & $5.61 \times 10^{-10}$ & 0.41 & 1.29 & $9.73 \times 10^{-10}$ & $1.10 \times 10^{-3}$ \\
\hline $4 q 22$ & FAM13A & rs4416442 & C & 0.40 & 1.38 & $6.87 \times 10^{-10}$ & 0.41 & 1.29 & $6.97 \times 10^{-10}$ & $2.30 \times 10^{-3}$ \\
\hline $4 q 22$ & FAM13A & rs7671167 & $\mathrm{T}$ & 0.50 & 1.35 & $5.58 \times 10^{-9}$ & 0.50 & 1.25 & $6.63 \times 10^{-8}$ & $3.00 \times 10^{-4}$ \\
\hline $4 q 22$ & FAM13A & rs1964516 & $\mathrm{T}$ & 0.50 & 1.35 & $1.04 \times 10^{-8}$ & 0.50 & 1.24 & $1.12 \times 10^{-7}$ & $8.00 \times 10^{-4}$ \\
\hline $4 q 31$ & HHIP-ASI & rs13141641 ${ }^{\dagger}$ & $\mathrm{T}$ & 0.58 & 1.27 & $2.81 \times 10^{-6}$ & 0.59 & 1.25 & $2.18 \times 10^{-8}$ & $1.77 \times 10^{-1}$ \\
\hline $4 q 31$ & HHIP-ASI & rs13118928 & A & 0.58 & 1.24 & $2.72 \times 10^{-5}$ & 0.59 & 1.25 & $3.15 \times 10^{-8}$ & $4.54 \times 10^{-1}$ \\
\hline $15 q 25$ & CHRNA3 & rs12914385 & $\mathrm{T}$ & 0.42 & 1.27 & $2.83 \times 10^{-6}$ & 0.42 & 1.22 & $7.86 \times 10^{-7}$ & $5.75 \times 10^{-2}$ \\
\hline $15 q 25$ & AGPHDI & rs8034191 & C & 0.37 & 1.27 & $4.29 \times 10^{-6}$ & 0.37 & 1.22 & $1.34 \times 10^{-6}$ & $5.13 \times 10^{-2}$ \\
\hline $15 q 25$ & IREB2 & rs11858836 & A & 0.35 & 1.25 & $4.10 \times 10^{-5}$ & 0.36 & 1.23 & $9.27 \times 10^{-7}$ & $4.19 \times 10^{-1}$ \\
\hline $19 q 13$ & $R A B 4 B$ & rs2604894 & G & 0.56 & 1.19 & $9.89 \times 10^{-4}$ & 0.57 & 1.16 & $4.70 \times 10^{-4}$ & $1.28 \times 10^{-1}$ \\
\hline $14 q 32$ & RIN3 & rs754388 & C & 0.81 & 1.22 & $3.74 \times 10^{-3}$ & 0.82 & 1.29 & $2.37 \times 10^{-6}$ & $5.84 \times 10^{-2}$ \\
\hline $14 q 32$ & RIN3 & rs17184313 & C & 0.82 & 1.20 & $6.85 \times 10^{-3}$ & 0.83 & 1.28 & $4.36 \times 10^{-6}$ & $1.92 \times 10^{-2}$ \\
\hline
\end{tabular}

Definition of abbreviations: $F R Q$ risk allele frequency; OR odds ratio; SNP single nucleotide polymorphism.

${ }^{*}$ Cho MH, et al. Variants in FAM13A Are Associated With Chronic Obstructive Pulmonary Disease. Nat Genet 2010;42:200-202.

${ }^{\dagger} \mathrm{Cho} \mathrm{MH}$, et al. unpublished data.

${ }^{\ddagger}$ Cho MH, et al. A Genome-Wide Association Study of COPD Identifies a Susceptibility Locus on Chromosome 19q13. Hum Mol Genet 2012;21:947-957.

${ }^{5}$ Pillai SG, et al. A Genome-Wide Association Study in Chronic Obstructive Pulmonary Disease (COPD): Identification of Two Major Susceptibility Loci.

PLoS Genet 2009;5:e1000421. 
In the primary meta-analysis of $\mathrm{CB}$ COPD relative to smoking controls, we found the strongest signal within FAM13A rather than the other known COPD susceptibility genes, and permutation testing confirmed that ORs of FAM13A SNPs were significantly higher than those for non-CB COPD. While COPD is a complex disease with marked phenotypic heterogeneity, most previous genetic studies have dealt with COPD subjects as one homogeneous group [20-22]. The current study suggests that previously identified COPD risk alleles might have different effects on the development of different COPD subtypes.

Although our secondary meta-analysis of $\mathrm{CB}$ COPD relative to $C O P D$ without $\mathrm{CB}$ within the $\mathrm{COPD}$ population failed to demonstrate genome-wide significant SNPs, the fourth most significant SNP, rs2298019, was previously identified as an expression quantitative trait locus (eQTL) for ATF6 in lung tissue [51], with the risk allele associated with decreased expression. ATF6 plays a major role in transcriptional repression of endogenous cystic fibrosis transmembrane conductance regulator (CFTR) under endoplasmic reticulum stress [52] and is thought to be a potential therapeutic target for cystic fibrosis (CF) [53]. In addition to CF, suppressed CFTR function has been reported in cigarette smokers and COPD patients without CF [54,55]. Recently, roflumilast, approved to reduce COPD exacerbations in COPD patients with $\mathrm{CB}$, has been reported to activate CFTR [56]. Since ATF6 is closely connected with CFTR, genetic variants of ATF6 may play a role in the pathogenesis of $\mathrm{CB}$.

We found that SNPs in another gene (CYS1) on 2p25.1 demonstrated suggestive associations for CB. CYS1 is enriched in the ciliary axoneme, and high expression in the kidney and weak expression in the lung were reported [57]. While the top SNP, rs12692398 of CYS1, reached the genome-wide significance threshold in both a GWAS of only COPDGene NHWs and a meta-analysis of COPDGene NHWs and GenKOLS, it lost significance in the metaanalysis of all three cohorts $\left(P=1.66 \times 10^{-4}\right)$. It is unclear why the association evidence for $\mathrm{CB}$ of this genomic region within ECLIPSE was negative. In the meta-analysis of three cohorts, the other two SNPs of CYS1, rs13000481 and rs4574084 showed $P$ values of $1.74 \times 10^{-5}$ and $2.61 \times 10^{-5}$, respectively, and LD between these two SNPs is high (0.94).

Our study has several limitations. First, we have not identified the functional genetic variants within our association regions. Nevertheless, we found significant differences in radiological parameters related to airway wall thickness according to genotypes of the novel top SNP, rs34391416, within COPDGene. These CT parameters have been frequently used as objective indicators of airway disease $[6,58]$. Interestingly, there were no differences in emphysema severity or distribution according to this SNP genotype. Further studies will be required to identify the functional genetic variants within this region and to determine which gene that they influence. Second, we have not performed any independent replication, although this analysis was a meta-analysis of three GWASs. However, a supplemental meta-analysis of four cohorts by adding COPDGene AAs also showed similar results as those of three cohorts. Third, CB was present in some of our smoking controls. However, an additional meta-analysis of three GWASs of CB COPD versus smoking controls without $\mathrm{CB}$ showed similar results.

\section{Conclusions}

We have identified a novel locus on 11p15.5, which includes several biologically plausible candidates (EFCAB4A, CHID1 and AP2A2) as potential CB susceptibility genes. We have also found significantly increased effect sizes of FAM13A SNPs in COPD subjects with CB compared to those without $\mathrm{CB}$. Although our secondary GWAS of $\mathrm{CB}$ versus no $\mathrm{CB}$ within $\mathrm{COPD}$ subjects did not show genomewide significant SNPs, a locus including ATF6 should be explored for its related functional consequences. This study supports the concept that different genetic susceptibility contributes to phenotypic heterogeneity within COPD.

\section{Additional file}

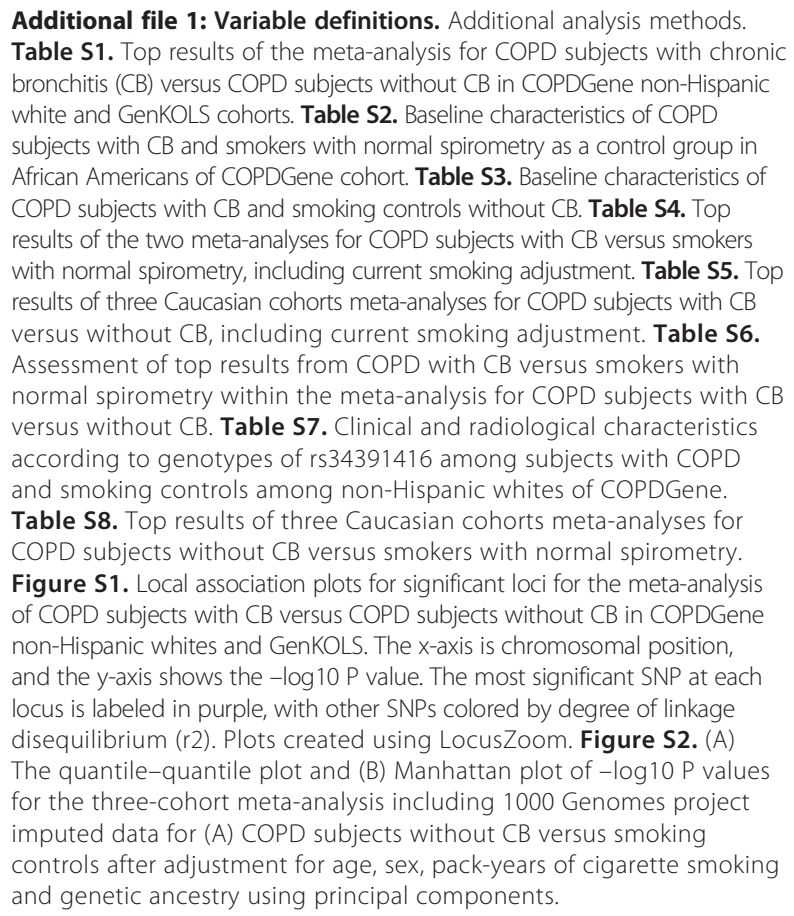

\section{Abbreviations}

AA: African American; CB: Chronic bronchitis; ECLIPSE: Evaluation of COPD longitudinally to identify predictive surrogate endpoints; GOLD: Global initiative for chronic obstructive lung disease; GWAS: Genome-wide association study; NHW: non-Hispanic white; SNP: Single nucleotide polymorphism. 


\section{Competing interests}

$J H L, M N M, J D C, P S B, A G, A P C, C H W$ and DAL have no competing interests related to the subject of the manuscript. EKS reports grants from $\mathrm{NIH}$, grants and other support from COPD Foundation, grants and personal fees from GlaxoSmithKline, during the conduct of the study; personal fees from Merck and travel support from Novartis, outside the submitted work. MHC has received $\mathrm{NIH}$ grant and consulted for Merck (outside the submitted work). $\mathrm{CPH}$ has received NIH grant and consulted for Novartis, CSL Behring (outside the submitted work). VK has participated in clinical trials sponsored by Boehringer Ingelheim, Glaxo-Smith-Kline, and Roche pharmaceuticals.

\section{Authors' contributions}

$J H L$ and EKS conceived of the study, participated in its design and drafted the manuscript. MHC, CPH, JDC, MNM, DAL, EKS, PSB, AG, APC, CHW, VK participated in data acquisition and quality control. JHL, MHC, MNM, CPH, PSB, CHW, DAL, EKS participated in analysis and interpretation. All authors made critical revisions of the manuscript and approved the final manuscript.

\section{Acknowledgements}

This work was supported by NIH R01 HL089856 (EKS), P01 HL105339 (EKS), and R01HL089897 (JDC) The COPDGene study (NCT00608764) is also supported by the COPD Foundation through contributions made to an Industry Advisory Board comprised of AstraZeneca, Boehringer Ingelheim, Novartis, Pfizer, Siemens, GlaxoSmithKline, and Sunovion. The Norway GenKOLS study (Genetics of Chronic Obstructive Lung Disease, GSK code RES11080) and the ECLIPSE study (NCT00292552; GSK code SCO104960) were sponsored by GlaxoSmithKline.

We acknowledge and thank the COPDGene Core Teams:

Administrative Core: James D. Crapo, MD (PI); Edwin K. Silverman, MD, PhD (PI); Barry J. Make, MD; Elizabeth A. Regan, MD, PhD; Stephanie Bratschie, MPH; Rochelle Lantz; Sandra Melanson, MSW, LCSW; Lori Stepp Executive Committee: Terri Beaty, PhD; Russell P. Bowler, MD, PhD; James D. Crapo, MD; Jeffrey L. Curtis, MD; Douglas Everett, PhD; MeiLan K. Han, MD, MS; John E. Hokanson, MPH, PhD; David Lynch, MB; Barry J. Make, MD; Elizabeth A. Regan, MD, PhD; Edwin K. Silverman, MD, PhD; E. Rand Sutherland, MD

External Advisory Committee: Eugene R. Bleecker, MD; Harvey O. Coxson, PhD; Ronald G. Crystal, MD; James C. Hogg, MD; Michael A. Province, PhD; Stephen I. Rennard, MD; Duncan C. Thomas, PhD NHLBl: Thomas Croxton, MD, PhD; Weiniu Gan, PhD; Lisa Postow, PhD COPD Foundation: John W. Walsh; Randel Plant; Delia Prieto Biorepository Visit 1 (Baltimore): Homayoon Farzadegan, PhD; Samantha Bragan; Stacey Cayetano

Biorepository Visit 2 (Boston): Daniel Cossette; Roxanne K. Kelly, MBA Data Coordinating Center: Douglas Everett, PhD; Andre Williams, PhD; Ruthie Knowles; Carla Wilson, MS

Epidemiology Core: John Hokanson, MPH, PhD; Jennifer Black-Shinn, MPH; Gregory Kinney, MPH

Genetic Analysis Core: Terri Beaty, PhD; Peter J. Castaldi, MD, MSc; Michael Cho, MD; Dawn L. DeMeo, MD, MPH; Marilyn G. Foreman, MD, MS; Nadia N. Hansel, MD, MPH; Megan E. Hardin, MD; Craig Hersh, MD, MPH; Jacqueline Hetmanski, MS; John E. Hokanson, MPH, PhD; Nan Laird, PhD; Christoph Lange, PhD; Sharon M. Lutz, MPH, PhD; Manuel Mattheisen, MD; Merry-Lynn McDonald, MSc, PhD; Margaret M. Parker, MHS; Elizabeth A. Regan, MD, PhD; Stephanie Santorico, PhD; Edwin K. Silverman, MD, PhD; Emily S. Wan, MD; Jin Zhou, PhD Genotyping Cores: Genome-Wide Core: Terri Beaty, PhD; Candidate Genotyping Core: Craig P. Hersh, MD, MPH; Edwin K. Silverman, MD, PhD Imaging Core: David Lynch, MB; Mustafa Al Qaisi, MD; Jaleh Akhavan; Christian W. Cox, MD; Harvey O. Coxson, PhD; Deanna Cusick; Jennifer G. Dy, PhD; Shoshana Ginsburg, MS; Eric A. Hoffman, PhD; Philip F. Judy, PhD; Alex Kluiber; Alexander McKenzie; John D. Newell, Jr., MD; John J. Reilly, Jr., MD; James Ross, MSc; Raul San Jose Estepar, PhD; Joyce D. Schroeder, MD; Jered Sieren; Arkadiusz Sitek, PhD; Douglas Stinson; Edwin van Beek, MD, PhD, MEd; George R. Washko, MD; Jordan Zach

PFT QA Core: Robert Jensen, PhD; E. Rand Sutherland, MD Biological Repository, Johns Hopkins University, Baltimore, MD: Homayoon Farzadegan, PhD: Samantha Bragan; Stacey Cayetano We further wish to acknowledge the COPDGene Investigators from the participating Clinical Centers: Ann Arbor VA: Jeffrey Curtis, MD, Ella Kazerooni, MD Baylor College of Medicine, Houston, TX: Nicola Hanania, MD, MS, Philip Alapat, MD, Venkata Bandi, MD, Kalpalatha Guntupalli, MD, Elizabeth Guy,
MD, Antara Mallampalli, MD, Charles Trinh, MD, Mustafa Atik, MD, Hasan Al-Azzawi, MD, Marc Willis, DO, Susan Pinero, MD, Linda Fahr, MD, Arun Nachiappan, MD, Collin Bray, MD, L. Alexander Frigini, MD, Carlos Farinas, MD, David Katz, MD, Jose Freytes, MD, Anne Marie Marciel, MD Brigham and Women's Hospital, Boston, MA: Dawn DeMeo, MD, MPH, Craig Hersh, MD, MPH, George Washko, MD, Francine Jacobson, MD, MPH, Hiroto Hatabu, MD, PhD, Peter Clarke, MD, Ritu Gill, MD, Andetta Hunsaker, MD, Beatrice Trotman-Dickenson, MBBS, Rachna Madan, MD

Columbia University, New York, NY: R. Graham Barr, MD, DrPH, Byron Thomashow, MD, John Austin, MD, Belinda D'Souza, MD

Duke University Medical Center, Durham, NC: Neil MacIntyre, Jr., MD, Lacey Washington, MD, H Page McAdams, MD

Reliant Medical Group, Worcester, MA: Richard Rosiello, MD, Timothy Bresnahan, MD, Joseph Bradley, MD, Sharon Kuong, MD, Steven Meller, MD, Suzanne Roland, MD

Health Partners Research Foundation, Minneapolis, MN: Charlene McEvoy, MD, $\mathrm{MPH}$, Joseph Tashjian, MD

Johns Hopkins University, Baltimore, MD: Robert Wise, MD, Nadia Hansel, MD, $\mathrm{MPH}$, Robert Brown, MD, Gregory Diette, MD, Karen Horton, MD

Los Angeles Biomedical Research Institute at Harbor UCLA Medical Center, Los Angeles, CA: Richard Casaburi, MD, Janos Porszasz, MD, PhD, Hans Fischer, MD, PhD, Matt Budoff, MD, Mehdi Rambod, MD

Michael E. DeBakey VAMC, Houston, TX: Amir Sharafkhaneh, MD, Charles Trinh, MD, Hirani Kamal, MD, Roham Darvishi, MD, Marc Willis, DO, Susan Pinero, MD, Linda Fahr, MD, Arun Nachiappan, MD, Collin Bray, MD, L. Alexander Frigini, MD, Carlos Farinas, MD, David Katz, MD, Jose Freytes, MD, Anne Marie Marciel, MD

Minneapolis VA: Dennis Niewoehner, MD, Quentin Anderson, MD, Kathryn Rice, MD, Audrey Caine, MD

Morehouse School of Medicine, Atlanta, GA: Marilyn Foreman, MD, MS, Gloria Westney, MD, MS, Eugene Berkowitz, MD, PhD

National Jewish Health, Denver, CO: Russell Bowler, MD, PhD, David Lynch, MB, Joyce Schroeder, MD, Valerie Hale, MD, John Armstrong, II, MD, Debra Dyer, MD, Jonathan Chung, MD, Christian Cox, MD

Temple University, Philadelphia, PA: Gerard Criner, MD, Victor Kim, MD, Nathaniel Marchetti, DO, Aditi Satti, MD, A. James Mamary, MD, Robert Steiner, MD, Chandra Dass, MD, Libby Cone, MD

University of Alabama, Birmingham, AL: William Bailey, MD, Mark Dransfield, MD, Michael Wells, MD, Surya Bhatt, MD, Hrudaya Nath, MD, Satinder Singh, MD

University of California, San Diego, CA: Joe Ramsdell, MD, Paul Friedman, MD University of lowa, lowa City, IA: Alejandro Cornellas, MD, John Newell, Jr., MD, Edwin JR van Beek, MD, PhD

University of Michigan, Ann Arbor, Ml: Fernando Martinez, MD, MeiLan Han, $M D$, Ella Kazerooni, MD

University of Minnesota, Minneapolis, MN: Christine Wendt, MD, Tadashi Allen, MD University of Pittsburgh, Pittsburgh, PA: Frank Sciurba, MD, Joel Weissfeld, MD, MPH, Carl Fuhrman, MD, Jessica Bon, MD, Danielle Hooper, MD University of Texas Health Science Center at San Antonio, San Antonio, TX: Antonio Anzueto, MD, Sandra Adams, MD, Carlos Orozco, MD, Mario Ruiz, MD, Amy Mumbower, MD, Ariel Kruger, MD, Carlos Restrepo, MD, Michael Lane, MD We acknowledge and thank ECLIPSE investigators:

Investigators — Bulgaria: Y. Ivanov, Pleven; K. Kostov, Sofia. Canada: J. Bourbeau, Montreal; M. Fitzgerald, Vancouver, BC; P. Hernandez, Halifax, NS; K. Killian, Hamilton, ON; R. Levy, Vancouver, BC; F. Maltais, Montreal; D. O'Donnell, Kingston, ON. Czech Republic: J. Krepelka, Prague. Denmark: J. Vestbo, Hvidovre. The Netherlands: E. Wouters, Horn-Maastricht. New Zealand: D. Quinn, Wellington. Norway: P. Bakke, Bergen. Slovenia: M. Kosnik, Golnik. Spain: A. Agusti, J. Sauleda, P. de Mallorca. Ukraine: Y. Feschenko, V. Gavrisyuk, L. Yashina, Kiev; N. Monogarova, Donetsk. United Kingdom: P. Calverley, Liverpool; D. Lomas, Cambridge; W. MacNee, Edinburgh; D. Singh, Manchester; J. Wedzicha, London. United States: A. Anzueto, San Antonio, TX; S. Braman, Providence, Rl; R. Casaburi, Torrance CA; B. Celli, Boston; G. Giessel, Richmond VA; M. Gotfried, Phoenix, AZ; G. Greenwald, Rancho Mirage, CA; N. Hanania, Houston; D. Mahler, Lebanon, NH; B. Make, Denver; S. Rennard, Omaha, NE; C. Rochester, New Haven, CT; P. Scanlon, Rochester, MN; D. Schuller, Omaha, NE; F. Sciurba, Pittsburgh; A. Sharafkhaneh, Houston; T. Siler, St. Charles, MO; E. Silverman, Boston; A. Wanner, Miami; R. Wise, Baltimore; R. ZuWallack, Hartford, CT. Steering Committee: H. Coxson (Canada), C. Crim (GlaxoSmithKline, USA), L. Edwards (GlaxoSmithKline, USA), D. Lomas (UK), W. MacNee (UK), E. Silverman (USA), R. Tal Singer (Co-chair, GlaxoSmithKline, USA), J. Vestbo (Co-chair, 
Denmark), J. Yates (GlaxoSmithKline, USA).

Scientific Committee: A. Agusti (Spain), P. Calverley (UK), B. Celli (USA), C. Crim (GlaxoSmithKline, USA), B. Miller (GlaxoSmithKline, USA), W. MacNee (Chair, UK), S. Rennard (USA), R. Tal-Singer (GlaxoSmithKline, USA), E. Wouters (The Netherlands), J. Yates (GlaxoSmithKline, USA).

\section{Author details}

${ }^{1}$ Channing Division of Network Medicine, Brigham and Women's Hospital, Boston, MA, USA. ${ }^{2}$ Division of Pulmonary and Critical Care Medicine, Department of Internal Medicine, School of Medicine, Ewha Womans University, Seoul, South Korea. ${ }^{3}$ Division of Pulmonary and Critical Care Medicine, Brigham and Women's Hospital, Boston, MA, USA. ${ }^{4}$ National Jewish Health, Denver, CO, USA. ${ }^{5}$ Department of Clinical Science, University of Bergen, Bergen, Norway. ${ }^{6}$ Department of Thoracic Medicine, Haukeland University Hospital, Bergen, Norway. 'Department of Pulmonary Medicine, University of lowa, lowa City, IA, USA. ${ }^{8}$ Department of Medicine, VA Medical Center, University of Minnesota, Minneapolis, MN, USA. ${ }^{9}$ Wolfson Institute for Biomedical Research, University College London, London, UK. ${ }^{10}$ Temple University School of Medicine, Philadelphia, PA, USA.

Received: 10 June 2014 Accepted: 2 September 2014

Published online: 21 September 2014

\section{References}

1. Hallberg J, Dominicus A, Eriksson UK, Gerhardsson de Verdier M, Pedersen NL, Dahlback M, Nihlen U, Higenbottam T, Svartengren M: Interaction between smoking and genetic factors in the development of chronic bronchitis. Am J Respir Crit Care Med 2008, 177:486-490.

2. Burrows B, Fletcher CM, Heard BE, Jones NL, Wootliff JS: The emphysematous and bronchial types of chronic airways obstruction. A clinicopathological study of patients in London and Chicago. Lancet 1966, 1:830-835

3. Ferre A, Fuhrman C, Zureik M, Chouaid C, Vergnenegre A, Huchon G, Delmas MC, Roche N: Chronic bronchitis in the general population: influence of age, gender and socio-economic conditions. Respir Med 2012, 106:467-471.

4. Patel BD, Coxson HO, Pillai SG, Agusti AG, Calverley PM, Donner CF, Make BJ, Muller NL, Rennard SI, Vestbo J, Wouters EF, Hiorns MP, Nakano Y, Camp PG, Nasute Fauerbach PV, Screaton NJ, Campbell EJ, Anderson WH, Paré PD, Levy RD, Lake SL, Silverman EK, Lomas DA, International COPD Genetics Network: Airway wall thickening and emphysema show independent familial aggregation in chronic obstructive pulmonary disease. Am J Respir Crit Care Med 2008, 178:500-505.

5. Kong X, Cho MH, Anderson W, Coxson HO, Muller N, Washko G, Hoffman EA, Bakke P, Gulsvik A, Lomas DA, Silverman EK, Pillai SG, ECLIPSE Study NETT Investigators: Genome-wide association study identifies BICD1 as a susceptibility gene for emphysema. Am J Respir Crit Care Med 2011 183:43-49.

6. Kim V, Han MK, Vance GB, Make BJ, Newell JD, Hokanson JE, Hersh CP, Stinson D, Silverman EK, Criner GJ: The chronic bronchitic phenotype of COPD: an analysis of the COPDGene Study. Chest 2011, 140:626-633.

7. Kim V, Garfield JL, Grabianowski CL, Krahnke JS, Gaughan JP, Jacobs MR, Criner GJ: The effect of chronic sputum production on respiratory symptoms in severe COPD. COPD 2011, 8:114-120.

8. Burgel PR, Nesme-Meyer P, Chanez P, Caillaud D, Carre P, Perez T, Roche N: Cough and sputum production are associated with frequent exacerbations and hospitalizations in COPD subjects. Chest 2009, 135:975-982.

9. Silverman EK, Mosley JD, Palmer LJ, Barth M, Senter JM, Brown A, Drazen JM, Kwiatkowski DJ, Chapman HA, Campbell EJ, Province MA, Rao DC, Reilly JJ, Ginns LC, Speizer FE, Weiss ST: Genome-wide linkage analysis of severe, early-onset chronic obstructive pulmonary disease: airflow obstruction and chronic bronchitis phenotypes. Hum Mol Genet 2002, 11:623-632

10. Zhu G, Agusti A, Gulsvik A, Bakke P, Coxson H, Lomas DA, Silverman EK, Pillai SG: CTLA4 gene polymorphisms are associated with chronic bronchitis. Eur Respir J 2009, 34:598-604.

11. Dijkstra AE, Smolonska J, van den Berge M, Wijmenga C, Zanen P, Luinge MA, Platteel M, Lammers JW, Dahlback M, Tosh K, Hiemstra PS, Sterk PJ, Spira A, Vestbo J, Nordestgaard BG, Benn M, Nielsen SF, Dahl M, Verschuren WM, Picavet HS, Smit HA, Owsijewitsch M, Kauczor HU, de Koning HJ, Nizankowska-Mogilnicka E, Mejza F, Nastalek P, van Diemen CC, Cho MH,
Silverman EK, et al: Susceptibility to chronic mucus hypersecretion, a genome wide association study. PLoS One 2014, 9:e91621.

12. Vestbo J, Anderson W, Coxson HO, Crim C, Dawber F, Edwards L, Hagan G, Knobil K, Lomas DA, MacNee W, Silverman EK, Tal-Singer R, ECLIPSE investigators: Evaluation of COPD Longitudinally to Identify Predictive Surrogate End-points (ECLIPSE). Eur Respir J 2008, 31:869-873.

13. Regan EA, Hokanson JE, Murphy JR, Make B, Lynch DA, Beaty TH, Curran-Everett D, Silverman EK, Crapo JD: Genetic epidemiology of COPD (COPDGene) study design. COPD 2010, 7:32-43.

14. Zhu G, Warren L, Aponte J, Gulsvik A, Bakke P, Anderson WH, Lomas DA, Silverman EK, Pillai SG: The SERPINE2 gene is associated with chronic obstructive pulmonary disease in two large populations. Am J Respir Crit Care Med 2007, 176:167-173.

15. Society AT: Chronic bronchitis, asthma and pulmonary emphysema: a statement by the Committee on Diagnostic Standards for Nontuberculous Respiratory Diseases. Am Rev Respir Dis 1962, 85:762-768.

16. Vestbo J, Hurd SS, Agusti AG, Jones PW, Vogelmeier C, Anzueto A, Barnes PJ, Fabbri LM, Martinez FJ, Nishimura M, Stockley RA, Sin DD, RodriguezRoisin R: Global strategy for the diagnosis, management, and prevention of chronic obstructive pulmonary disease: GOLD executive summary. Am J Respir Crit Care Med 2013, 187:347-365.

17. Li Y, Willer CJ, Ding J, Scheet P, Abecasis GR: MaCH: using sequence and genotype data to estimate haplotypes and unobserved genotypes. Genet Epidemiol 2010, 34:816-834

18. Howie B, Fuchsberger C, Stephens M, Marchini J, Abecasis GR: Fast and accurate genotype imputation in genome-wide association studies through pre-phasing. Nat Genet 2012, 44:955-959.

19. Abecasis GR, Auton A, Brooks LD, DePristo MA, Durbin RM, Handsaker RE, Kang HM, Marth GT, McVean GA: An integrated map of genetic variation from 1,092 human genomes. Nature 2012, 491:56-65.

20. Pillai SG, Ge D, Zhu G, Kong X, Shianna KV, Need AC, Feng S, Hersh CP, Bakke P, Gulsvik A, Ruppert A, Lødrup Carlsen KC, Roses A, Anderson W, Rennard SI, Lomas DA, Silverman EK, Goldstein DB, ICGN Investigators: A genome-wide association study in chronic obstructive pulmonary disease (COPD): identification of two major susceptibility loci. PLoS Genet 2009, 5:e1000421.

21. Cho MH, Boutaoui N, Klanderman BJ, Sylvia JS, Ziniti JP, Hersh CP, DeMeo DL, Hunninghake GM, Litonjua AA, Sparrow D, Lange C, Won S, Murphy JR, Beaty TH, Regan EA, Make BJ, Hokanson JE, Crapo JD, Kong X, Anderson WH, Tal-Singer R, Lomas DA, Bakke P, Gulsvik A, Pillai SG, Silverman EK: Variants in FAM13A are associated with chronic obstructive pulmonary disease. Nat Genet 2010, 42:200-202.

22. Cho MH, Castaldi PJ, Wan ES, Siedlinski M, Hersh CP, DeMeo DL, Himes BE, Sylvia JS, Klanderman BJ, Ziniti JP, Lange C, Litonjua AA, Sparrow D, Regan EA, Make BJ, Hokanson JE, Murray T, Hetmanski JB, Pillai SG, Kong X, Anderson WH, Tal-Singer R, Lomas DA, Coxson HO, Edwards LD, MacNee W, Vestbo J, Yates JC, Agusti A, Calverley PM: A genome-wide association study of COPD identifies a susceptibility locus on chromosome 19q13. Hum Mol Genet 2012, 21:947-957.

23. Cho MH, McDonald ML, Zhou X, Mattheisen M, Castaldi PJ, Hersh CP, Demeo DL, Sylvia JS, Ziniti J, Laird NM, Lange C, Litonjua AA, Sparrow D, Casaburi R, Barr RG, Regan EA, Make BJ, Hokanson JE, Lutz S, Dudenkov TM, Farzadegan H, Hetmanski JB, Tal-Singer R, Lomas DA, Bakke P, Gulsvik A, Crapo JD, Silverman EK, Beaty TH, NEIT Genetics, ICGN, ECLIPSE and COPDGene Investigators: Risk loci for chronic obstructive pulmonary disease: a genomewide association study and meta-analysis. Lancet Respir Med 2014, 2:214-225.

24. Purcell $S$, Neale B, Todd-Brown K, Thomas L, Ferreira MA, Bender D, Maller J, Sklar P, de Bakker PI, Daly MJ, Sham PC: PLINK: a tool set for wholegenome association and population-based linkage analyses. Am J Hum Genet 2007, 81:559-575.

25. de Bakker PI, Ferreira MA, Jia X, Neale BM, Raychaudhuri S, Voight BF: Practical aspects of imputation-driven meta-analysis of genome-wide association studies. Hum Mol Genet 2008, 17:R122-R128.

26. Willer CJ, Li Y, Abecasis GR: METAL: fast and efficient meta-analysis of genomewide association scans. Bioinformatics 2010, 26:2190-2191.

27. Higgins JP, Thompson SG, Deeks JJ, Altman DG: Measuring inconsistency in meta-analyses. BMJ 2003, 327:557-560.

28. Han B, Eskin E: Random-effects model aimed at discovering associations in meta-analysis of genome-wide association studies. Am J Hum Genet 2011, 88:586-598. 
29. Devlin B, Roeder K: Genomic control for association studies. Biometrics 1999, 55:997-1004

30. Aulchenko YS, Ripke S, Isaacs A, van Duijn CM: GenABEL: an R library for genome-wide association analysis. Bioinformatics 2007, 23:1294-1296.

31. Pruim RJ, Welch RP, Sanna S, Teslovich TM, Chines PS, Gliedt TP, Boehnke M, Abecasis GR, Willer CJ: LocusZoom: regional visualization of genome-wide association scan results. Bioinformatics 2010, 26:2336-2337.

32. Hancock DB, Artigas MS, Gharib SA, Henry A, Manichaikul A, Ramasamy A, Loth DW, Imboden M, Koch B, McArdle WL, Smith AV, Smolonska J, Sood A, Tang W, Wilk JB, Zhai G, Zhao JH, Aschard H, Burkart KM, Curjuric Eijgelsheim M, Elliott P, Gu X, Harris TB, Janson C, Homuth G, Hysi PG, Liu JZ, Loehr LR, Lohman K, et al: Genome-wide joint meta-analysis of SNP and SNP-by-smoking interaction identifies novel loci for pulmonary function. PLoS Genet 2012, 8:e1003098.

33. Hancock DB, Eijgelsheim M, Wilk JB, Gharib SA, Loehr LR, Marciante KD, Franceschini N, van Durme YM, Chen TH, Barr RG, Schabath MB, Couper DJ, Brusselle GG, Psaty BM, van Duijn CM, Rotter Jl, Uitterlinden AG, Hofman A, Punjabi NM, Rivadeneira F, Morrison AC, Enright PL, North KE, Heckbert SR, Lumley T, Stricker BH, O'Connor GT, London SJ: Meta-analyses of genome-wide association studies identify multiple loci associated with pulmonary function. Nat Genet 2010,42:45-52

34. Rose MC, Voynow JA: Respiratory tract mucin genes and mucin glycoproteins in health and disease. Physiol Rev 2006, 86:245-278.

35. Thai $P$, Loukoianov A, Wachi $S$, Wu R: Regulation of airway mucin gene expression. Annu Rev Physiol 2008, 70:405-429.

36. Rossi AH, Salmon WC, Chua M, Davis CW: Calcium signaling in human airway goblet cells following purinergic activation. Am J Physiol Lung Cell Mol Physiol 2007, 292:L92-L98.

37. Manral S, Bhatia S, Sinha R, Kumar A, Rohil V, Arya A, Dhawan A, Arya P, Joshi R, Sreedhara SC, Gangopadhyay S, Bansal SK, Chatterjee S, Chaudhury NK, Vijayan VK, Saso L, Parmar VS, DePass AL, Prasad AK, Raj HG Normalization of deranged signal transduction in lymphocytes of COPD patients by the novel calcium channel blocker H-DHPM. Biochimie 2011, 93:1146-1156.

38. Ross AJ, Dailey LA, Brighton LE, Devlin RB: Transcriptional profiling of mucociliary differentiation in human airway epithelial cells. Am J Respir Cell Mol Biol 2007, 37:169-185.

39. Yanai I, Benjamin H, Shmoish M, Chalifa-Caspi V, Shklar M, Ophir R, Bar-Even A, Horn-Saban S, Safran M, Domany E, Lancet D, Shmueli O: Genome-wide midrange transcription profiles reveal expression level relationships in human tissue specification. Bioinformatics 2005, 21:650-659.

40. Meng G, Zhao Y, Bai X, Liu Y, Green TJ, Luo M, Zheng X: Structure of human stabilin-1 interacting chitinase-like protein (SI-CLP) reveals a saccharide-binding cleft with lower sugar-binding selectivity. J Biol Chem 2010, 285:39898-39904.

41. Kzhyshkowska J, Mamidi S, Gratchev A, Kremmer E, Schmuttermaier C, Krusell L, Haus G, Utikal J, Schledzewski K, Scholtze J, Goerdt S: Novel stabilin-1 interacting chitinase-like protein (SI-CLP) is up-regulated in alternatively activated macrophages and secreted via lysosomal pathway. Blood 2006, 107:3221-3228.

42. Lee CG, Da Silva CA, Lee JY, Hartl D, Elias JA: Chitin regulation of immune responses: an old molecule with new roles. Curr Opin Immunol 2008, 20:684-689.

43. Letuve S, Kozhich A, Humbles A, Brewah Y, Dombret MC, Grandsaigne M, Adle H, Kolbeck R, Aubier M, Coyle AJ, Pretolani M: Lung chitinolytic activity and chitotriosidase are elevated in chronic obstructive pulmonary disease and contribute to lung inflammation. Am J Pathol 2010, 176:638-649.

44. Letuve S, Kozhich A, Arouche N, Grandsaigne M, Reed J, Dombret MC, Kiener PA, Aubier M, Coyle AJ, Pretolani M: YKL-40 is elevated in patients with chronic obstructive pulmonary disease and activates alveolar macrophages. J Immunol 2008, 181:5167-5173.

45. Aminuddin F, Akhabir L, Stefanowicz D, Pare PD, Connett JE, Anthonisen NR, Fahy JV, Seibold MA, Burchard EG, Eng C, Gulsvik A, Bakke P, Cho MH, Litonjua A, Lomas DA, Anderson WH, Beaty TH, Crapo JD, Silverman EK, Sandford AJ: Genetic association between human chitinases and lung function in COPD. Hum Genet 2012, 131:1105-1114.

46. Chen H, Fre S, Slepnev VI, Capua MR, Takei K, Butler MH, Di Fiore PP, De CP: Epsin is an EH-domain-binding protein implicated in clathrin-mediated endocytosis. Nature 1998, 394:793-797.
47. Okabayashi Y, Sugimoto Y, Totty NF, Hsuan J, Kido Y, Sakaguchi K, Gout I, Waterfield MD, Kasuga M: Interaction of Shc with adaptor protein adaptins. J Biol Chem 1996, 271:5265-5269.

48. Gosalia N, Leir SH, Harris A: Coordinate regulation of the gel-forming mucin genes at chromosome 11p15.5. J Biol Chem 2013, 288:6717-6725

49. Vinall LE, Fowler JC, Jones AL, Kirkbride HJ, de BC, Laine A, Porchet N, Gum JR, Kim YS, Moss FM, Mitchell DM, Swallow DM: Polymorphism of human mucin genes in chest disease: possible significance of MUC2. Am J Respir Cell Mol Biol 2000, 23:678-686.

50. Rousseau K, Byrne C, Griesinger G, Leung A, Chung A, Hill AS, Swallow DM: Allelic association and recombination hotspots in the mucin gene (MUC) complex on chromosome 11p15.5. Ann Hum Genet 2007, 71:561-569.

51. Hao K, Bosse Y, Nickle DC, Pare PD, Postma DS, Laviolette M, Sandford A, Hackett TL, Daley D, Hogg JC, Elliott WM, Couture C, Lamontagne M, Brandsma CA, van den Berge M, Koppelman G, Reicin AS, Nicholson DW, Malkov V, Derry JM, Suver C, Tsou JA, Kulkarni A, Zhang C, Vessey R, Opiteck GJ, Curtis SP, Timens W, Sin DD: Lung eQTLs to help reveal the molecular underpinnings of asthma. PLoS Genet 2012, 8:e1003029.

52. Bartoszewski R, Rab A, Twitty G, Stevenson L, Fortenberry J, Piotrowski A, Dumanski JP, Bebok Z: The mechanism of cystic fibrosis transmembrane conductance regulator transcriptional repression during the unfolded protein response. J Biol Chem 2008, 283:12154-12165.

53. Kerbiriou M, Le Drevo MA, Ferec C, Trouve P: Coupling cystic fibrosis to endoplasmic reticulum stress: differential role of Grp78 and ATF6. Biochim Biophys Acta 2007, 1772:1236-1249.

54. Cantin AM, Hanrahan JW, Bilodeau G, Ellis L, Dupuis A, Liao J, Zielenski J, Durie $P$ : Cystic fibrosis transmembrane conductance regulator function is suppressed in cigarette smokers. Am J Respir Crit Care Med 2006, 173:1139-1144.

55. Dransfield MT, Wilhelm AM, Flanagan B, Courville C, Tidwell SL, Raju SV, Gaggar A, Steele C, Tang LP, Liu B, Rowe SM: Acquired cystic fibrosis transmembrane conductance regulator dysfunction in the lower airways in COPD. Chest 2013, 144:498-506.

56. Lambert JA, Raju SV, Tang LP, McNicholas CM, Li Y, Courville CA, Farris RF, Coricor GE, Smoot LH, Mazur MM, Dransfield MT, Bolger GB, Rowe SM: Cystic fibrosis transmembrane conductance regulator activation by roflumilast contributes to therapeutic benefit in chronic bronchitis. Am J Respir Cell Mol Biol 2014, 50:549-558.

57. Fliegauf M, Frohlich C, Horvath J, Olbrich H, Hildebrandt F, Omran H: Identification of the human CYS1 gene and candidate gene analysis in Boichis disease. Pediatr Nephrol 2003, 18:498-505.

58. Orlandi I, Moroni C, Camiciottoli G, Bartolucci M, Pistolesi M, Villari N, Mascalchi M: Chronic obstructive pulmonary disease: thin-section $\mathrm{CT}$ measurement of airway wall thickness and lung attenuation. Radiology 2005, 234:604-610.

doi:10.1186/s12931-014-0113-2

Cite this article as: Lee et al:: Genetic susceptibility for chronic bronchitis in chronic obstructive pulmonary disease. Respiratory Research 2014 15:113.

\section{Submit your next manuscript to BioMed Central and take full advantage of:}

- Convenient online submission

- Thorough peer review

- No space constraints or color figure charges

- Immediate publication on acceptance

- Inclusion in PubMed, CAS, Scopus and Google Scholar

- Research which is freely available for redistribution

Submit your manuscript at www.biomedcentral.com/submit
C Biomed Central 